\title{
BMJ Open Outcomes of direct and indirect medical intensive care unit admissions from the emergency department of an acute care hospital: a retrospective cohort study
}

\author{
Joseph Antonio D Molina, ${ }^{1}$ Eillyne Seow, ${ }^{2}$ Bee Hoon Heng, ${ }^{1}$ Wai Fung Chong, ${ }^{1}$ \\ Benjamin $\mathrm{Ho}^{3}$
}

To cite: Molina JAD, Seow E, Heng $\mathrm{BH}$, et al. Outcomes of direct and indirect medical intensive care unit admissions from the emergency department of an acute care hospital: a retrospective cohort study. BMJ Open 2014:4:e005553. doi:10.1136/bmjopen-2014005553

- Prepublication history for this paper is available online. To view these files please visit the journal online (http://dx.doi.org/10.1136/ bmjopen-2014-005553).

Received 25 April 2014 Revised 15 August 2014 Accepted 8 September 2014

\section{CrossMark}

${ }^{1}$ Health Services \& Outcomes Research, National Healthcare Group, Singapore, Singapore 2Emergency Department, Tan Tock Seng Hospital, Singapore, Singapore ${ }^{3}$ Department of Respiratory and Critical Care Medicine, Tan Tock Seng Hospital, Singapore, Singapore

\section{Correspondence to} Dr Joseph Antonio D Molina; Joseph_Antonio_Molina@ nhg.com.sg

\section{ABSTRACT}

Objectives: This study aimed to determine if the risk of adverse outcomes (in-hospital and 60-day mortality, intensive care unit (ICU) and total hospital length of stay (LOS)) was greater for medical ICU (MICU) or high dependency unit (HDU) patients indirectly admitted from the emergency department (ED) than for directly admitted patients.

Setting: This study was conducted at a large public acute care hospital in Singapore.

Participants: In this retrospective cohort study, hospital records of patients who were admitted directly from the $E D$, or initially admitted to the general wards from the ED and subsequently transferred to the MICU/HDU within $24 \mathrm{~h}$, were reviewed. Patients were included if they were: (A) discharged from the MICU/HDU in 2009 and were admitted from the ED and (B) transferred to the MICU/ HDU within $24 \mathrm{~h}$ of presentation at the ED. Data from 706 patients were analysed; $58.4 \%$ were men with a median age of 61 years.

\section{Primary and secondary outcome measures:}

The following outcomes were compared: in-hospital mortality, 60-day mortality, LOS at the MICU/HDU, as well as total hospital LOS.

Results: Of the 706 patients, 491 (69.5\%) were directly admitted to the MICU/HDU. After adjusting for demographics, comorbidities, interventions at the ED and clinical parameters at the ED (heart rate, respiration,

oxygen saturation, mean arterial pressure), as well as the Apache II score on arrival at the MICU/HDU, indirectly admitted patients had a higher risk of in-hospital mortality (OR=3.07, $95 \% \mathrm{Cl} 1.39$ to 6.80 ), death within 60 days (OR=3.09, $95 \% \mathrm{Cl} 1.40$ to 6.83 ) and risk of staying $>1$ day at the MICU/HDU (OR=2.54,

$95 \% \mathrm{Cl} 1.48$ to 4.36$)$. There was no significant difference in total in-hospital LOS.

Conclusions: Indirectly admitted MICU/HDU patients had generally poorer outcomes. As the magnitude of effect may vary across settings, context-specific studies may be useful for improving outcomes.

\section{INTRODUCTION}

In recent decades, healthcare has become more and more expensive, triggering calls

\section{Strengths and limitations of this study}

- This health services research focused on patientimportant outcomes including mortality and length of hospital stay.

- Unlike other studies, this research focused on the effect of indirect admissions (admission to the general wards before transfer to the intensive care unit (ICU)) rather than on the effect of admission delays.

- Only patients admitted to the ICU within $24 \mathrm{~h}$ of arrival at the emergency department were included in the study to minimise bias resulting from differences in disease severity/prognosis on presentation.

- While this study confirms other study findings of a detrimental effect of delayed/indirect admission, more importantly it suggests that differences in the magnitude of effect across institutions are due to factors intrinsic to each health facility and that these contributory factors must be addressed at the level of the individual institution.

- Owing to limitations in the data, it was not possible to determine the reason for the initial refusal of indirect medical ICU/high dependency unit admissions.

for cost-effective care in an increasingly costconscious and quality-conscious environment. Intensive care unit (ICU) beds are scarce hospital resources reserved for a select subset of hospital patients. Underlying the scarcity of ICU beds is the high start-up and operating cost of the unit as well as the highly specialised training required of the staff. While the total cost of ICU admission varies widely, the daily cost of ICU care per patient is approximately three to four times more than that in the general ward. ${ }^{1-4}$ Despite ICU beds comprising only between $1.2-6.3 \%$ of all hospital beds, ICU services are estimated to take up $15-20 \%$ of the total hospital budget. ${ }^{5}$ Given the scarcity of ICU beds, priority is given to patients with serious but potentially reversible conditions who may benefit from more intensive observation and 
treatment than is provided in the general ward. ${ }^{4}{ }^{6}$ To a certain extent, guidelines can reduce the arbitrariness of triaging patients to the ICU. However, the ultimate decision to admit a patient to the ICU depends largely on the individual physician's preference, professional judgement and experience. A benchmarking study found a wide variation across ICUs in the proportion of critical care patients admitted for active critical care treatment versus monitoring alone. ${ }^{7}$ Depending on the institution, between $20 \%$ and $98 \%$ of patients admitted to the ICU required active treatment. ${ }^{7}$

The benefits gained from the ICU as a scarce resource can be maximised not just through the right siting of care, but also by ensuring that critically ill patients are admitted without delay. Numerous factors have been cited for delays in admitting critically ill patients from the emergency department (ED) to the ICU. Commonly implicated factors include the lack of available ICU beds, ${ }^{8-12}$ the underlying disease itself, ${ }^{8} 13$ organisational issues $^{9}$ and frontline health professionals' inability to recognise the seriousness of the condition. ${ }^{14}{ }^{15}$ Regardless of the cause, delayed ICU admissions may ultimately have the same detrimental effect on the patient.

This study aimed to determine if severely ill patients indirectly admitted from the ED to the general wards and subsequently to the medical ICU (MICU) or high dependency unit (HDU) have a greater risk of adverse outcomes than those who were admitted directly from the ED to the MICU or HDU. The main outcomes of interest included in-hospital and 60-day mortality, ICU as well as total hospital length of stay.

\section{METHODS}

\section{Plan of investigation}

This was a retrospective cohort study conducted in a tertiary level acute care public hospital in Singapore.

In this hospital, after assessing the patient's need for ICU care, the ED physician refers the patient to the intensivist on-call. The intensivist makes his own assessment at the ED and makes the final decision on where to admit the patient. This decision is based mainly on the intensivist's expert judgement as well as his awareness of current ICU bed availability. A bed is then requested in the unit specified by the intensivist.

All patients admitted to the MICU or HDU within $24 \mathrm{~h}$ of presentation at the ED between January and December 2009, and who were admitted under the following medical specialties, were eligible for inclusion: general medicine; respiratory medicine; infectious disease; gastroenterology; psychiatry; rheumatology, allergy and immunology; medical oncology; rehabilitation medicine and geriatric medicine. Patients who would have been admitted to the MICU/HDU under the aforementioned specialties, but were admitted to other critical care units because of the unavailability of beds, were likewise included. Patients who were admitted under cardiology, neurology and other surgical specialties were excluded as these specialties manage their own ICU and the nature of intensive care required for these patients would have been different from that required for general MICU patients.

Patients were classified into direct and indirect admissions. Direct admissions comprised patients admitted directly to the MICU/HDU within $24 \mathrm{~h}$ of presentation at the ED. Patients who were initially admitted to the wards and subsequently transferred to the MICU/HDU within $24 \mathrm{~h}$ of presentation at the ED were considered indirect admissions. A previous study ${ }^{15}$ showed that the in-hospital mortality rate for indirectly admitted patients was $44 \%$ with a relative risk of 1.41 . At a direct to indirect admission ratio of $1: 1$, confidence level of $95 \%$, power of $80 \%$ and minimum effect size of $12.8 \%$, the estimated minimum sample size was 480 patients.

In-hospital mortality, 60-day mortality, MICU/HDU and total in-hospital length of stay were compared between the two groups. Except for deaths within 60 days of admission, data on the independent and dependent variables as well as selected covariates were extracted from the Operations Data Store hospital administrative database, ED, MICU and HDU case notes. Sixty-day mortality was requested from the Ministry of Health, Singapore. Data extraction was performed by one trained research assistant. Data were periodically reviewed by the investigator for completeness and were subjected to logic checks.

\section{Analysis}

Analysis was conducted with PASW Statistics Release V.18.0 (IBM, New York). Aside from baseline patient characteristics, the proportion of direct and indirect MICU/HDU admissions relative to total MICU/HDU admissions were generated using descriptive statistics. Outcomes were expressed as dichotomous variables with an MICU/HDU length of stay categorised into $<2$ and $2+$ days, and an in-hospital length of stay categorised into $<8$ and $8+$ days. Possible associations between an admitting unit and each outcome were explored through univariate analysis. Adjusted effect measures between the timing of admission to the MICU/HDU (direct or indirect) and each outcome were analysed using two sets of logistic regression models. The primary analyses included all patients regardless of the reason for admission to the ICU. The secondary analyses excluded patients with hypotension, respiratory failure or those who were intubated-conditions considered as strong indications for ICU admission. In the secondary analyses, the total hospital length of stay and ICU length of stay were analysed as continuous variables using Cox proportional hazard. Interval estimates of ORs for categories of the independent variable and identified covariates were generated. Effect measures were adjusted for the following covariates:

- Age.

- Gender.

- Charlson comorbidity index (CCI) based on a history of the following: acute myocardial infarction, congestive heart failure, peripheral vascular disease, 
cerebrovascular disease, dementia, chronic pulmonary disease, connective tissue disease, peptic ulcer disease, mild liver disease, moderate to severe liver disease, hemiplegia, moderate to severe renal disease, any tumour within the past 5 years, metastatic solid tumour, lymphoma, leukaemia, diabetes, diabetes with end organ damage and AIDS.

- Acute Physiology and Chronic Health Evaluation II (APACHE II) score on arrival at the MICU/HDU;

- Recent (7 days) discharge from the hospital prior to current admission.

- Objective parameters on presentation at the ED including heart rate, respiratory rate, oxygen saturation, mean arterial pressure.

- Resuscitation efforts at the ED.

- Intubation at the ED.

- Admission at the MICU versus HDU.

\section{RESULTS}

\section{Baseline characteristics}

Table 1 presents the baseline characteristics of direct and indirect admissions. There were 706 patients admitted to the MICU/HDU within $24 \mathrm{~h}$ of presentation at the ED in 2009. Of these, more than two-thirds were admitted directly from the ED to the MICU/HDU with the rest having been admitted to the general wards before their subsequent transfer. Compared with indirect admissions, a significantly greater proportion of those directly admitted underwent resuscitation and intubation at the ED. However, those indirectly admitted were older, had more comorbidities and were significantly more likely to be admitted to the MICU than the HDU. Time from ED presentation to MICU/HDU admission was more than four times longer for indirect admissions.
Clinical and laboratory findings of patients on arrival at the ED are presented in table 2. Aside from pneumonia, which was the most common diagnosis at the ED, chronic airway obstruction was among the five leading diagnoses for direct and indirect ICU admissions. Respiratory distress was the most common reason for admission to the ICU. Intubation, hypotension and severe acidosis were other common reasons for admission to the ICU for directly and indirectly admitted patients. The following laboratory parameters were significantly lower for direct ICU admissions: $\mathrm{pH}$, calcium, urea and creatinine; while the following were significantly higher for direct ICU admissions: $\mathrm{PaO}_{2}$, sodium, haemoglobin and haematocrit.

\section{Main results}

Univariate analysis of outcomes by the admitting unit

Regardless of which critical care unit the patient was admitted to (MICU and HDU taken together), direct admissions had a lower in-hospital mortality, lower 60-day mortality, were less likely to stay in the unit for more than 1 day and were less likely to stay in the hospital for more than 1 week.

Looking at results separately for MICU and HDU, patients directly admitted from the ED to the MICU had a lower in-hospital mortality and 60-day mortality, and were less likely to stay in the hospital for more than 1 week than those indirectly admitted (figure 1 ). For those admitted to the HDU, directly admitted patients likewise had a lower in-hospital mortality and 60-day mortality, but were less likely to stay in the unit for more than 1 day. Among all direct admissions, in-hospital mortality and 60-day mortality were higher for patients admitted to the MICU than for those admitted to the HDU. In addition, MICU patients were

Table 1 Baseline characteristics of patients directly and indirectly admitted to the ICU/MICU

\begin{tabular}{|c|c|c|c|c|}
\hline Characteristic & $\begin{array}{l}\text { All patients } \\
\mathrm{N}=706\end{array}$ & $\begin{array}{l}\text { Direct admissions } \\
\mathrm{n}=491\end{array}$ & $\begin{array}{l}\text { Indirect admissions } \\
\mathrm{n}=215\end{array}$ & p Value \\
\hline \multicolumn{5}{|l|}{ Age } \\
\hline Mean* (SD) & $59.72(17.6)$ & $58.6(18.3)$ & $62.3(15.7)$ & 0.006 \\
\hline Median & 61 & 61 & 62 & \\
\hline \multicolumn{5}{|l|}{ Gender, N (\%) } \\
\hline Male & $412(58.4)$ & $288(58.8)$ & $124(57.4)$ & 0.808 \\
\hline Female & $294(41.6)$ & $203(41.3)$ & $91(42.3)$ & \\
\hline Ethnicity, N (\%) & $470(66.6)$ & $326(66.4)$ & $144(67.0)$ & 0.085 \\
\hline Chinese & $104(14.7)$ & $64(13.0)$ & $40(18.6)$ & \\
\hline Malay & 89 (12.6) & $65(13.2)$ & $24(11.2)$ & \\
\hline Indian & $3(0.4)$ & $2(0.4)$ & $1(0.5)$ & \\
\hline Eurasian & $40(5.6)$ & $34(6.9)$ & $6(2.8)$ & \\
\hline \multicolumn{5}{|l|}{ Others } \\
\hline Presented at the ED in the preceding 7 days, $\mathrm{N}(\%)$ & $22(3.1)$ & $17(3.5)$ & $5(2.3)$ & 0.424 \\
\hline Hospitalised in the preceding 7 days, $\mathrm{N}(\%)$ & $30(4.2)$ & $20(4.1)$ & $10(4.7)$ & 0.726 \\
\hline Underwent resuscitation at the $\mathrm{ED}^{*}, \mathrm{~N}(\%)$ & $34(4.8)$ & $34(6.9)$ & $0(0.0)$ & 0.000 \\
\hline Underwent intubation at the ED*, N (\%) & $223(31.6)$ & $223(45.3)$ & $0(0.0)$ & 0.000 \\
\hline Admitted to the MICU (vs HDU)* ${ }^{\star}, \mathrm{N}(\%)$ & $445(63.8)$ & $296(60.4)$ & $149(71.6)$ & 0.005 \\
\hline Charlson comorbidity index ${ }^{\star}$, median & 1.0 & 1.0 & 2.0 & 0.000 \\
\hline Hours from arrival at the ED to ICU admission*, median & 2.51 & 1.97 & 9.20 & 0.000 \\
\hline
\end{tabular}


Table 2 Baseline clinical and laboratory findings of patients directly and indirectly admitted to the ICU/MICU

\begin{tabular}{|c|c|c|c|c|c|c|c|}
\hline \multicolumn{2}{|l|}{ Baseline clinical finding } & \multicolumn{2}{|c|}{$\begin{array}{l}\text { All patients } \\
\mathrm{N}=706\end{array}$} & \multicolumn{2}{|c|}{$\begin{array}{l}\text { Direct admissions } \\
\mathrm{n}=491\end{array}$} & \multicolumn{2}{|c|}{$\begin{array}{l}\text { Indirect admissions } \\
\mathrm{n}=\mathbf{2 1 5}\end{array}$} \\
\hline \multirow{5}{*}{\multicolumn{2}{|c|}{ Most common presenting diagnoses }} & \multicolumn{2}{|c|}{ Pneumonia } & \multicolumn{2}{|c|}{ Unspecified infection } & \multicolumn{2}{|c|}{ Pneumonia } \\
\hline & & \multirow{2}{*}{\multicolumn{2}{|c|}{$\begin{array}{l}\text { Unspecified infection } \\
\text { Chronic airway obstruction }\end{array}$}} & \multicolumn{2}{|c|}{ Pneumonia } & \multicolumn{2}{|c|}{ Chronic airway obstruction } \\
\hline & & & & Asthm & & Myocar & tion \\
\hline & & \multicolumn{2}{|c|}{ Asthma } & \multicolumn{2}{|c|}{ Chronic airway obstruction } & \multicolumn{2}{|c|}{ Diabetes } \\
\hline & & \multicolumn{2}{|c|}{ Fluid overload } & \multicolumn{2}{|c|}{ Fluid overload } & \multicolumn{2}{|c|}{ Chronic kidney disease } \\
\hline \multirow{5}{*}{\multicolumn{2}{|c|}{ Most common reasons for ICU admission }} & \multirow{2}{*}{\multicolumn{2}{|c|}{$\begin{array}{l}\text { Respiratory distress } \\
\text { Severe acidosis }\end{array}$}} & \multicolumn{2}{|c|}{ Severe acidosis } & \multicolumn{2}{|c|}{ Respiratory distress } \\
\hline & & & & \multicolumn{2}{|c|}{ Respiratory distress } & \multicolumn{2}{|c|}{ Urgent dialysis } \\
\hline & & \multicolumn{2}{|c|}{ Intubated patient } & Intubat & & Intubate & \\
\hline & & \multirow{2}{*}{\multicolumn{2}{|c|}{$\begin{array}{l}\text { Hypotension } \\
\text { Altered mental state }\end{array}$}} & \multirow{2}{*}{\multicolumn{2}{|c|}{$\begin{array}{l}\text { Hypotension } \\
\text { Altered mental state }\end{array}$}} & \multirow{2}{*}{\multicolumn{2}{|c|}{$\begin{array}{l}\text { Hypotension } \\
\text { Severe acidosis }\end{array}$}} \\
\hline & & & & & & & \\
\hline \multirow[b]{2}{*}{ Baseline laboratory } & \multicolumn{3}{|c|}{ Direct admissions $(n=491)$} & \multicolumn{3}{|c|}{ Indirect admissions $(\mathrm{n}=215)$} & \multirow[b]{2}{*}{ p Value } \\
\hline & $\overline{\mathbf{N}}$ & Result & SD & $\overline{\mathbf{N}}$ & Result & SD & \\
\hline Arterial pH & 424 & 7.2 & 0.19 & 81 & 7.3 & 0.15 & 0.000 \\
\hline $\mathrm{PaO}_{2}(\mathrm{~mm} \mathrm{Hg})$ & 419 & 152.9 & 125.55 & 72 & 104.8 & 59.51 & 0.002 \\
\hline Sodium (mmol/dL) & 482 & 136.1 & 6.3 & 204 & 134.3 & 6.79 & 0.001 \\
\hline Potassium (mmol/dL) & 481 & 4.6 & 1.33 & 203 & 4.5 & 1.25 & 0.149 \\
\hline Calcium (mmol/dL) & 324 & 1.4 & 0.5 & 78 & 1.7 & 0.65 & 0.000 \\
\hline Glucose (mmol/dL) & 378 & 12 & 8.22 & 150 & 10.6 & 6.25 & 0.057 \\
\hline Urea (mmol/dL) & 480 & 13 & 12.71 & 204 & 19.05 & 19.22 & 0.000 \\
\hline Creatinine $(\mu \mathrm{mol} / \mathrm{dL})$ & 480 & 297.3 & 354.59 & 200 & 405.7 & 415.59 & 0.001 \\
\hline Bicarbonate (mmol/dL) & 418 & 20.5 & 10.36 & 78 & 19.2 & 9.61 & 0.307 \\
\hline Haemoglobin (g/dL) & 482 & 12.6 & 3.06 & 205 & 11.4 & 2.97 & 0.000 \\
\hline Haematocrit (\%) & 482 & 37.4 & 9.14 & 205 & 34.1 & 8.9 & 0.000 \\
\hline Total white cells $\left(\times 10^{9} / \mathrm{L}\right)$ & 474 & 14.3 & 10.28 & 205 & 13.3 & 9.96 & 0.238 \\
\hline
\end{tabular}

more likely than HDU patients to stay in the unit for more than 1 day.

\section{Multivariate results}

1. All patients

A. In-hospital mortality: Patients admitted to the general wards before subsequent transfer to the MICU/HDU had a threefold increased risk of in-hospital death (table 3(1)). In-hospital mortality was likewise significantly associated with increasing age and with resuscitation at the ED. None of the other covariates were significantly associated with in-hospital death.

B. Death within 60 days of admission: The risk of dying within 60 days of admission was three times higher for indirectly admitted patients. Increasing age and resuscitation at the ED were likewise associated with increased 60-day

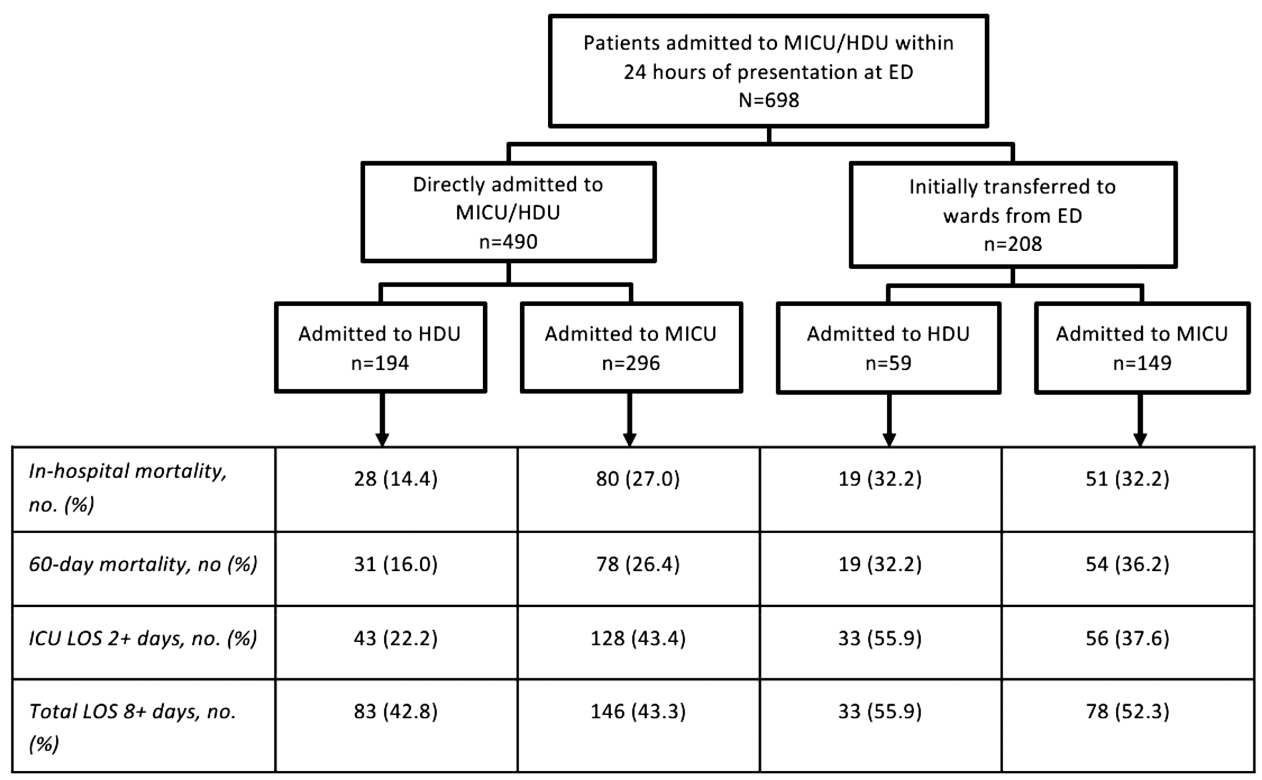

Figure 1 Outcomes of direct and indirect admissions, by unit (HDU, high dependency unit; ICU, intensive care unit; MICU, medical ICU; ED, emergency department; LOS, length of stay). 
Table 3 Adjusted results for the effect of indirect MICU/HDU admissions on selected outcomes (all patients)

\begin{tabular}{|c|c|c|c|}
\hline Factor & OR $(95 \% \mathrm{CI})$ & Factor & OR $(95 \% \mathrm{Cl})$ \\
\hline (1) Outcome: in-hospital mortality & & Yes & $0.62(0.22$ to 1.77$)$ \\
\hline Admission to the ICU & & No (Ref) & - \\
\hline Indirect & 3.07 (1.39 to 6.80$)$ & Gender & \\
\hline Direct (Ref) & - & Female & $0.93(0.49$ to 1.78$)$ \\
\hline Charlson comorbidity index & $0.95(0.80$ to 1.14$)$ & Male (Ref) & - \\
\hline Age & $1.02(1.01$ to 1.04$)$ & Heart rate at the ED & \\
\hline Hospitalisation within the past & & $70-109$ & $0.71(0.28$ to 1.81$)$ \\
\hline 7 days & & $110-129$ or $50-69$ & $0.58(0.23$ to 1.47$)$ \\
\hline Yes & $1.15(0.30$ to 4.39$)$ & $140+$ or $<55$ (Ref) & - \\
\hline No (Ref) & - & Respiratory rate at the ED & \\
\hline Cardiopulmonary resuscitation & & $12-24$ & $0.65(0.17$ to 2.47$)$ \\
\hline Yes & 37.38 (6.89 to 202.70$)$ & $<12$ or $>24$ (Ref) & - \\
\hline No (Ref) & - & Oxygen saturation at the ED & \\
\hline Intubation at the ED & & $<98$ & $1.40(0.75$ to 2.61$)$ \\
\hline Yes & $0.90(0.33$ to 2.51$)$ & 98-100 (Ref) & - \\
\hline No (Ref) & - & Mean arterial pressure at the ED & \\
\hline Gender & & $70-109$ & $0.86(0.34$ to 2.18$)$ \\
\hline Female & $0.85(0.45$ to 1.61$)$ & $110-129$ or $50-69$ & $0.66(0.24$ to 1.78$)$ \\
\hline Male (Ref) & - & $130+$ or $<50$ (Ref) & - \\
\hline Heart rate at the ED & & Apache on arrival at the ICU & \\
\hline $70-109$ & $0.78(0.31$ to 1.96$)$ & 0-9 & 2.25 (0.63 to 8.02$)$ \\
\hline $110-129$ or $50-69$ & $0.64(0.26$ to 1.60$)$ & $10-14$ & $0.53(0.16$ to 1.77$)$ \\
\hline $140+$ or $<55$ (Ref) & - & $15-19$ & $1.21(0.44$ to 3.33$)$ \\
\hline Respiratory rate at the ED & & $20-24$ & $1.07(0.38$ to 3.05$)$ \\
\hline $12-24$ & $0.80(0.22$ to 2.95$)$ & $25-29$ & $0.81(0.24$ to 2.78$)$ \\
\hline$<12$ or >24 (Ref) & - & $30+($ Ref $)$ & - \\
\hline Oxygen saturation at the ED & & Where patient was admitted & \\
\hline$<98$ & $1.71(0.92$ to 3.17$)$ & ICU & $1.10(0.47$ to 2.54$)$ \\
\hline 98-100 (Ref) & - & HDU (Ref) & - \\
\hline Mean arterial pressure at the ED & & (3) Outcome: total in-hospital lengt & of stay \\
\hline $70-109$ & $1.31(0.51$ to 3.37$)$ & (8+ days vs 0-7 days) & \\
\hline $110-129$ or $50-69$ & $1.00(0.37$ to 2.75$)$ & Admission to the ICU & \\
\hline $130+$ or $<50$ (Ref) & - & Indirect & 0.80 (0.34 to 1.88$)$ \\
\hline Apache on arrival at the ICU & & Direct (Ref) & - \\
\hline $0-9$ & $2.08(0.60$ to 7.29$)$ & Charlson comorbidity index & $1.02(0.85$ to 1.24$)$ \\
\hline $10-14$ & $0.54(0.17$ to 1.71$)$ & Age & $1.03(1.01$ to 1.05$)$ \\
\hline $15-19$ & 0.88 (0.32 to 2.39$)$ & Hospitalisation within the past 7 & \\
\hline $20-24$ & $0.83(0.30$ to 2.31$)$ & days & \\
\hline $25-29$ & $0.78(0.24$ to 2.56$)$ & Yes & 0.85 (0.18 to 3.92$)$ \\
\hline $30+($ Ref $)$ & - & No (Ref) & - \\
\hline Where patient was admitted & & Intubation at the ED & \\
\hline $\mathrm{ICU}$ & $0.98(0.42$ to 2.26$)$ & Yes & $1.08(0.40$ to 2.89$)$ \\
\hline HDU (Ref) & - & No (Ref) & - \\
\hline (2) Outcome: death within 60 days & f admission & Gender & \\
\hline Admission to the ICU & & Female & $1.53(0.79$ to 2.94$)$ \\
\hline Indirect & 3.09 (1.40 to 6.83$)$ & Male (Ref) & - \\
\hline Direct (Ref) & - & Heart rate at the ED & \\
\hline Charlson comorbidity index & $1.00(0.84$ to 1.19$)$ & $70-109$ & 1.05 (0.37 to 3.03$)$ \\
\hline Age & $1.03(1.01$ to 1.05$)$ & $110-129$ or $50-69$ & $0.42(0.16$ to 1.15$)$ \\
\hline Hospitalisation within the past & & $140+$ or $<55$ (Ref) & - \\
\hline 7 days & & Respiratory rate at the ED & \\
\hline Yes & $1.12(0.29$ to 4.30$)$ & $12-24$ & $1.19(0.31$ to 4.46$)$ \\
\hline No (Ref) & - & $<12$ or $>24$ (Ref) & - \\
\hline Cardiopulmonary resuscitation & & Oxygen saturation at the ED & \\
\hline Yes & 51.39 (9.25 to 285.62$)$ & $<98$ & 1.05 (0.55 to 1.98$)$ \\
\hline No (Ref) & - & 98-100 (Ref) & - \\
\hline Intubation at the ED & & Mean arterial pressure at the ED & \\
\hline
\end{tabular}


Table 3 Continued

\begin{tabular}{|c|c|}
\hline Factor & OR $(95 \% \mathrm{Cl})$ \\
\hline 70-109 & 1.66 (0.66 to 4.17$)$ \\
\hline $110-129$ or $50-69$ & $1.75(0.68$ to 4.51$)$ \\
\hline $130+$ or $<50$ (Ref) & - \\
\hline \multicolumn{2}{|l|}{ Apache on arrival at the ICU } \\
\hline $0-9$ & 1.72 (0.36 to 8.14$)$ \\
\hline $10-14$ & $1.34(0.45$ to 3.96$)$ \\
\hline $15-19$ & $0.72(0.25$ to 2.07$)$ \\
\hline $20-24$ & $2.00(0.70$ to 5.74$)$ \\
\hline $25-29$ & 1.26 (0.36 to 4.42$)$ \\
\hline $30+($ Ref) & - \\
\hline \multicolumn{2}{|l|}{ Where patient was admitted } \\
\hline ICU & $1.65(0.68$ to 4.01$)$ \\
\hline HDU (Ref) & - \\
\hline \multirow{2}{*}{\multicolumn{2}{|c|}{$\begin{array}{l}\text { (4) Outcome: ICU/MICU length of stay (2+ vs } 0-1 \text { day) } \\
\text { Admission to the ICU }\end{array}$}} \\
\hline & \\
\hline Indirect & $2.54(1.48$ to 4.36$)$ \\
\hline Direct (Ref) & - \\
\hline Charlson comorbidity index & 0.85 (0.76 to 0.96$)$ \\
\hline Age & $1.01(1.00$ to 1.03$)$ \\
\hline \multicolumn{2}{|l|}{$\begin{array}{l}\text { Hospitalisation within the past } \\
7 \text { davs }\end{array}$} \\
\hline \multicolumn{2}{|l|}{7 days } \\
\hline Yes & 1.87 (0.69 to 5.07$)$ \\
\hline No (Ref) & - \\
\hline \multicolumn{2}{|l|}{ Cardiopulmonary resuscitation } \\
\hline Yes & 1.95 (0.36 to 10.52$)$ \\
\hline No (Ref) & - \\
\hline Intubation at the ED & 1.93 (1.02 to 3.68$)$ \\
\hline Intubated & - \\
\hline \multicolumn{2}{|l|}{ Not intubated (Ref) } \\
\hline Gender & 1.36 (0.89 to 2.07$)$ \\
\hline Female & - \\
\hline \multicolumn{2}{|l|}{ Male (Ref) } \\
\hline Heart rate at the ED & 1.83 (0.92 to 3.67$)$ \\
\hline 70-109 & $1.62(0.82$ to 3.21$)$ \\
\hline $110-129$ or $50-69$ & - \\
\hline $140+$ or $<55$ (Ref) & \\
\hline Respiratory rate at the ED & 0.90 (0.35 to 2.35$)$ \\
\hline $12-24$ & - \\
\hline \multicolumn{2}{|l|}{$<12$ or $>24$} \\
\hline Oxygen saturation at the ED & 1.94 (1.28 to 2.93$)$ \\
\hline$<98$ & - \\
\hline \multicolumn{2}{|l|}{ 98-100 (Ref) } \\
\hline Mean arterial pressure at the ED & 1.07 (0.58 to 1.97$)$ \\
\hline $70-109$ & 1.01 (0.53 to 1.92$)$ \\
\hline $110-129$ or $50-69$ & - \\
\hline $130+$ or $<50$ (Ref) & \\
\hline \multicolumn{2}{|l|}{ Where patient was admitted } \\
\hline ICU & 1.39 (0.80 to 2.43$)$ \\
\hline HDU (Ref) & - \\
\hline
\end{tabular}

ED, emergency department; HDU, high dependency unit; ICU, intensive care unit; MICU, medical ICU.

mortality (table 3(2)). There were no other significant predictors of 60-day mortality.

C. Total in-hospital length of stay ( $<8$ vs $8+$ days): After excluding patients who died during hospitalisation from the analysis, increasing age was the only variable associated with total in-hospital length of stay of 8 days or more (table $3(3)$ ). There was no significant difference in the total in-hospital length of stay for direct and indirect MICU/HDU admissions.

D. MICU/HDU length of stay (<2 vs $2+$ days): As with total in-hospital length of stay, patients who died during hospitalisation were excluded from the analysis. The risk of staying two or more days in the MICU/HDU was 2.5 times higher for indirectly admitted patients (table 3 (4)). Older patients, those with fewer comorbidities (lower CCI), with low oxygen saturation $(<98 \%)$ and those who were intubated at the ED were also more likely to stay for two or more days in the MICU/HDU.

2. All patients excluding those admitted to the ICU for hypotension, respiratory failure or who were intubated

A. In-hospital mortality: Of the 706 patients in the study, only 197 remained in the analysis after excluding patients with hypotension, respiratory failure or who were intubated. None of the factors tested, including direct/indirect admission, were significantly associated with in-hospital mortality (table 4(1)).

B. Death within 60 days of admission: With 197 patients included in the analysis, none of the factors included in the logistic regression model were significantly associated with mortality within 60 days of admission (table 4(2)).

C. Total in-hospital length of stay: After further excluding patients who died during hospitalisation, 178 patients remained in the analysis. Using Cox proportional hazards, lower CCI was the only variable associated with total in-hospital length of stay (table 4(3)). There was no significant difference in the total in-hospital length of stay for direct and indirect MICU/HDU admissions.

D. MICU/HDU length of stay: As with total in-hospital length of stay, patients who died during hospitalisation were excluded from the analysis. Results of Cox proportional hazards show that none of the factors, including direct/ indirect admission, were significantly associated with MICU/HDU length of stay (table 4(4)).

\section{DISCUSSION}

In this study, one-third of patients were indirectly admitted to the MICU/HDU. A multicentre study in the USA and Europe on patients with pneumonia revealed a similar indirect admission rate of $30.5 \% .^{16}$ A Brazilian study reported that $68.8 \%$ of admissions to the ICU were delaved as a result of indirect admissions to the ward, ${ }^{17}$ while a study from the UK found that $17.6 \%$ of ICU admissions were indirect transfers. ${ }^{18}$ However, the wide disparity in figures across settings may be related to the lack of a standard definition for indirect admission or admission delays. 
Table 4 Adjusted results for the effect of indirect MICU/HDU admissions on selected outcomes (all patients excluding those admitted to the ICU for hypotension, respiratory failure or who were intubated)

\begin{tabular}{|c|c|}
\hline Factor & OR $(95 \% \mathrm{Cl})$ \\
\hline \multicolumn{2}{|c|}{ (1) Outcome: in-hospital mortality } \\
\hline \multicolumn{2}{|l|}{ Admission to the ICU } \\
\hline Indirect & $10.67(0.76$ to 149.39$)$ \\
\hline Direct (Ref) & - \\
\hline Charlson comorbidity index & 0.72 (0.32 to 1.64$)$ \\
\hline Age & 0.99 (0.91 to 1.07$)$ \\
\hline \multicolumn{2}{|l|}{ Hospitalisation within the past } \\
\hline \multicolumn{2}{|l|}{7 days } \\
\hline No & 1.09 (0.05 to 22.43$)$ \\
\hline Yes (Ref) & - \\
\hline \multicolumn{2}{|l|}{ Gender } \\
\hline Female & 0.50 (0.41 to 6.05$)$ \\
\hline Male (Ref) & - \\
\hline \multicolumn{2}{|l|}{ Heart rate at the ED } \\
\hline $70-109$ & $0.43(0.01$ to 12.67$)$ \\
\hline $110-129$ or $50-69$ & $0.35(0.01$ to 14.94$)$ \\
\hline $140+$ or $<55$ (Ref) & - \\
\hline \multicolumn{2}{|l|}{ Respiratory rate at the ED } \\
\hline $12-24$ & $0.07(0.00$ to -$)$ \\
\hline$<12$ or $>24$ (Ref) & - \\
\hline \multicolumn{2}{|l|}{ Oxygen saturation at the ED } \\
\hline $98-100$ (Ref) & 2.24 (0.08 to 63.61) \\
\hline$<98$ & \\
\hline \multicolumn{2}{|c|}{ Mean arterial pressure at the ED } \\
\hline $70-109$ & $0.05(0.00$ to 5.41$)$ \\
\hline $110-129$ or $50-69$ & 0.01 (0.00 to 1.66$)$ \\
\hline $130+$ or $<50$ (Ref) & - \\
\hline \multicolumn{2}{|l|}{ Apache on arrival at the ICU } \\
\hline 0-9 & $0.23(0.00$ to 26.07$)$ \\
\hline $10-14$ & $0.00(0.00$ to -$)$ \\
\hline $15-19$ & $2.35(0.13$ to 41.91$)$ \\
\hline $20-24$ & $0.16(0.01$ to 4.95$)$ \\
\hline $25-29$ & $0.90(0.02$ to 48.44$)$ \\
\hline $30+($ Ref $)$ & - \\
\hline \multicolumn{2}{|l|}{ Where patient was admitted } \\
\hline $\mathrm{ICU}$ & 4.50 (0.14 to 142.83$)$ \\
\hline HDU (Ref) & - \\
\hline \multicolumn{2}{|l|}{ (2) Outcome: death within } \\
\hline \multicolumn{2}{|l|}{60 days of admission } \\
\hline \multicolumn{2}{|l|}{ Admission to the ICU } \\
\hline Indirect & 10.30 (0.83 to 128.02$)$ \\
\hline Direct (Ref) & - \\
\hline Charlson comorbidity index & $1.09(0.53$ to 2.24$)$ \\
\hline & $1.01(0.93$ to 1.10$)$ \\
\hline \multicolumn{2}{|l|}{ Hospitalisation within the past } \\
\hline \multicolumn{2}{|l|}{7 days } \\
\hline No & 1.09 (0.05 to 22.43$)$ \\
\hline Yes (Ref) & - \\
\hline \multicolumn{2}{|l|}{ Gender } \\
\hline Female & $0.22(0.02$ to 2.19$)$ \\
\hline Male (Ref) & - \\
\hline \multicolumn{2}{|l|}{ Heart rate at the ED } \\
\hline $70-109$ & $1.42(0.05$ to 39.37$)$ \\
\hline $110-129$ or $50-69$ & $0.33(0.01$ to 11.56$)$ \\
\hline $140+$ or $<55$ (Ref) & - \\
\hline
\end{tabular}

\begin{tabular}{|c|c|}
\hline Factor & OR $(95 \% \mathrm{Cl})$ \\
\hline \multicolumn{2}{|l|}{ Respiratory rate at the ED } \\
\hline $12-24$ & $0.31(0.00$ to -$)$ \\
\hline$<12$ or >24 (Ref) & - \\
\hline \multicolumn{2}{|l|}{ Oxygen saturation at the ED } \\
\hline $98-100$ & $0.63(0.05$ to 8.69$)$ \\
\hline$<98$ (Ref) & - \\
\hline \multicolumn{2}{|c|}{ Mean arterial pressure at the ED } \\
\hline $70-109$ & $0.16(0.00$ to 5.91$)$ \\
\hline $110-129$ or $50-69$ & $0.02(0.00$ to 1.30$)$ \\
\hline $130+$ or $<50$ (Ref) & - \\
\hline \multicolumn{2}{|l|}{ Apache on arrival at the ICU } \\
\hline $0-9$ & $1.13(0.02$ to 76.15$)$ \\
\hline $10-14$ & 0.00 (0.00 to -$)$ \\
\hline $15-19$ & 1.79 (0.12 to 26.97$)$ \\
\hline $20-24$ & $0.93(0.07$ to 12.44$)$ \\
\hline $25-29$ & 0.27 (0.01 to 15.54$)$ \\
\hline $30+($ Ref) & - \\
\hline \multicolumn{2}{|l|}{ Where patient was admitted } \\
\hline ICU & 2.00 (0.07 to 59.39$)$ \\
\hline HDU (Ref) & - \\
\hline \multicolumn{2}{|l|}{$\begin{array}{l}\text { (3) Outcome: total in-hospital } \\
\text { length of stay }\end{array}$} \\
\hline \multicolumn{2}{|l|}{ Admission to the ICU } \\
\hline Indirect & $1.06(0.51$ to 2.22$)$ \\
\hline Direct (Ref) & - \\
\hline Charlson comorbidity index & $0.76(0.59 \text { to } 0.96)^{*}$ \\
\hline Age & 1.00 (0.97 to 1.02$)$ \\
\hline \multicolumn{2}{|l|}{ Hospitalisation within the past } \\
\hline \multicolumn{2}{|l|}{7 days } \\
\hline Yes & 2.09 (0.57 to 7.72$)$ \\
\hline No (Ref) & - \\
\hline \multicolumn{2}{|l|}{ Gender } \\
\hline Female & 0.76 (0.39 to 1.49$)$ \\
\hline Male (Ref) & - \\
\hline \multicolumn{2}{|l|}{ Heart rate at the ED } \\
\hline 70-109 & $0.62(0.18$ to 2.15$)$ \\
\hline $110-129$ or $50-69$ & $1.46(0.40$ to 5.33$)$ \\
\hline $140+$ or $<55$ (Ref) & - \\
\hline \multicolumn{2}{|l|}{ Respiratory rate at the ED } \\
\hline $12-24$ & 2.58 (0.27 to 24.38$)$ \\
\hline$<12$ or >24 (Ref) & - \\
\hline \multicolumn{2}{|l|}{ Oxygen saturation at the ED } \\
\hline $98-100$ & 0.71 (0.31 to 1.62$)$ \\
\hline$<98$ (Ref) & - \\
\hline \multicolumn{2}{|c|}{ Mean arterial pressure at the ED } \\
\hline $70-109$ & $0.78(0.24$ to 2.54$)$ \\
\hline $110-129$ or $50-69$ & $0.64(0.19$ to 2.20$)$ \\
\hline $130+$ or $<50$ (Ref) & - \\
\hline \multicolumn{2}{|l|}{ Apache on arrival at the ICU } \\
\hline $0-9$ & $0.96(0.22$ to 4.30$)$ \\
\hline $10-14$ & 1.24 (0.45 to 3.38$)$ \\
\hline $15-19$ & 0.57 (0.20 to 1.64$)$ \\
\hline $20-24$ & 0.65 (0.24 to 1.82$)$ \\
\hline $25-29$ & 0.84 (0.21 to 3.32$)$ \\
\hline $30+($ Ref) & - \\
\hline
\end{tabular}


Table 4 Continued

\begin{tabular}{|c|c|}
\hline Factor & OR (95\% Cl) \\
\hline \multicolumn{2}{|l|}{ Where patient was admitted } \\
\hline ICU & $1.10(0.42$ to 2.91$)$ \\
\hline HDU (Ref) & - \\
\hline \multicolumn{2}{|c|}{$\begin{array}{l}\text { (4) Outcome: ICU/MICU length } \\
\text { of stay }\end{array}$} \\
\hline \multicolumn{2}{|l|}{ Admission to the ICU } \\
\hline Indirect & 0.94 (0.65 to 1.36$)$ \\
\hline Direct (Ref) & - \\
\hline Charlson comorbidity index & 1.01 (0.93 to 1.10$)$ \\
\hline Age & $1.00(0.99$ to 1.00$)$ \\
\hline \multicolumn{2}{|l|}{ Hospitalisation within the past } \\
\hline \multicolumn{2}{|l|}{7 days } \\
\hline No & 1.05 (0.45 to 2.46$)$ \\
\hline Yes (Ref) & - \\
\hline \multicolumn{2}{|l|}{ Gender } \\
\hline Female & $1.16(0.83$ to 1.61$)$ \\
\hline Male (Ref) & - \\
\hline \multicolumn{2}{|l|}{ Heart rate at the ED } \\
\hline 70-109 & 0.90 (0.50 to 1.63$)$ \\
\hline $110-129$ or $50-69$ & 0.77 (0.42 to 1.41$)$ \\
\hline $140+$ or $<55$ (Ref) & - \\
\hline \multicolumn{2}{|l|}{ Respiratory rate at the ED } \\
\hline $12-24$ & 2.98 (0.38 to 23.14$)$ \\
\hline <12 or >24 (Ref) & - \\
\hline \multicolumn{2}{|l|}{ Oxygen saturation at the ED } \\
\hline $98-100$ & 1.06 (0.73 to 1.52$)$ \\
\hline$<98$ (Ref) & - \\
\hline \multicolumn{2}{|c|}{ Mean arterial pressure at the ED } \\
\hline 70-109 & 1.00 (0.58 to 1.72$)$ \\
\hline $110-129$ or $50-69$ & 0.91 (0.50 to 1.64$)$ \\
\hline $130+$ or $<50$ (Ref) & - \\
\hline \multicolumn{2}{|l|}{ Where patient was admitted } \\
\hline ICU & $0.93(0.62$ to 1.39$)$ \\
\hline HDU (Ref) & - \\
\hline
\end{tabular}

Of the various independent variables considered in this study, indirect admission to intensive care was identified as one of the few which were independently associated with in-hospital mortality, death within 60 days of admission, and length of stay at the MICU/HDU. Other researchers had similar findings suggesting poor outcomes for patients indirectly admitted or whose admission was delayed. ${ }^{8} 1112$ 14-17 19-24

Establishing the magnitude of the problem as well as its consequences is an important first step towards planning for improvements. Planning specific interventions will require identification of the underlying reasons for indirect admissions and delays. While a full ICU is often implicated for delays, ${ }^{8-12}$ other reasons such as procedural standards and staffing issues, ${ }^{9}$ as well as the diagnosis and prognosis of the patient, ${ }^{8}{ }^{13}$ have been cited as reasons for refusal of admission. Inability to recognise the severity of the patient's condition has likewise been cited as a cause of delays in ICU admission. ${ }^{14}{ }^{15} \mathrm{~A}$ study which compared direct and indirect admissions noted that patients whose admission to the ICU were delayed were more likely to have been initially assessed by junior staff or less experienced intensivists. ${ }^{8}{ }^{23}$ In a survey of ICU physicians in Italy, $86 \%$ of the respondents acknowledged having admitted patients inappropriately, with $33 \%$ attributing this to clinical doubt and $25 \%$ to assessment error. ${ }^{25}$

The long list of possible causes of indirect ICU admissions and delays makes it a challenge to prioritise interventions because each cause calls for a different solution. To address the perennial problem of a full ICU, aside from the intuitive but operationally complex solution of increasing the number of beds, other recommendations include increasing the availability of intermediate or stepdown care $^{8}$ or alternative care areas for patients who require stabilisation $;{ }^{13}$ deployment of medical emergency teams or intensive care outreach services for ward patients becoming critically ill; ; ${ }^{13} \quad 2627$ and use of various models to expand physician coverage to provide critical care in the ED. ${ }^{28}$ Other factors and proposed interventions include the development of ward care pathways for conditions which frequently lead to ICU admissions ${ }^{15}$ and the development of predictive models and physiological early warning scores to identify incipient severe outcomes. ${ }^{16}{ }^{18}$ Bringing in some elements of intensive care such as ventilators to the general wards may not be enough to improve outcomes for critically ill patients. Tang found a significantly higher riskstandardised mortality among patients who were mechanically ventilated in the wards compared with the ICU. ${ }^{29}$

To enhance triage decisions, resources such as clinical guidelines are available for emergency physicians and intensivists to complement their professional judgement. Examples include the American College of Critical Care Medicine's Guidelines for ICU Admission, Discharge, and Triage, ${ }^{4}$ as well as Guidelines on Admission to and Discharge from the ICU and HDU of the UK Department of Health. ${ }^{30}$ The performance and accuracy of tools such as the Emergency Severity Index have been assessed. ${ }^{31}$ While, to a certain extent, existing tools minimise the subjectivity of patient assessments, there is a need to continuously improve the performance of these tools.

With regard to limitations of this research, as this was a retrospective study, it was not possible to determine the reason for the initial refusal of indirect MICU/HDU admissions. While the lack of ICU beds is perhaps the most commonly cited reason in the literature,${ }^{8-12}$ for this study the proportion of indirect admissions due to the unavailable MICU/HDU beds cannot be ascertained.

Differentiating direct from indirect admissions based solely on where the patient was initially admitted may introduce bias if no criterion is specified for the upper limit of the interval between arrival at the ED and admission to the MICU/HDU. There is no universally accepted duration which determines that a patient's condition is not expected to deteriorate to a point that transfer to the MICU/HDU becomes necessary soon after admission to the general ward. However, for this study, the $24 \mathrm{~h}$ upper 
limit from ED presentation to MICU/HDU admission was used as it was considered a reasonable interval during which a non-critical patient admitted to the general ward is expected to remain stable.

In the multivariate analysis, MICU and HDU patients were analysed as a single group as analysing them separately would have substantially reduced the sample size. While the magnitude of effects may differ between the two groups, bivariate results suggested similar directions of effect for MICU and HDU patients analysed separately.

This study validates previously published findings that indirect ICU admissions or delays lead to adverse patient outcomes. While the direction of effect may be consistent across settings, variations in the magnitude of effect may be affected by factors such as differences in ICU bed capacity, the profile of patients served, organisational procedures and standards, as well as physician characteristics. For this reason, the estimated risk of adverse outcomes in one setting will not necessarily apply to another, thus highlighting the usefulness of conducting similar studies in one's own context. These self-assessments enable emergency and ICU departments to customise improvements based on their unique situations. It also facilitates performance monitoring by providing a baseline measure of the adverse consequences of indirect admissions, against which future results may be compared.

Contributors ES, BHH and BH conceived the study. ES and BH facilitated and provided access to the data. All the authors designed the study. JADM and WFC designed and supervised data collection. JADM supervised data management and quality control and also analysed the data and drafted the manuscript. ES and BHH monitored the study's progress. All authors provided peer review and substantial inputs to the final form of the manuscript.

Funding This study was internally funded by the Emergency Department, Tan Tock Seng Hospital.

Competing interests None.

Ethics approval The research was approved by the Domain Specific Review Board of the National Healthcare Group (Singapore)

Provenance and peer review Not commissioned; externally peer reviewed.

Data sharing statement No additional data are available.

Open Access This is an Open Access article distributed in accordance with the Creative Commons Attribution Non Commercial (CC BY-NC 4.0) license, which permits others to distribute, remix, adapt, build upon this work noncommercially, and license their derivative works on different terms, provided the original work is properly cited and the use is non-commercial. See: http:// creativecommons.org/licenses/by-nc/4.0/

\section{REFERENCES}

1. Bonvissuto CA. Avoiding unnecessary critical care costs. Healthc Financ Manage 1994;48:47-8, 50, 52.

2. Ministry of Health NSW, Australia. Costs of care standards 2009/10. Ministry of Health, 2011.

3. Gyldmark M. A review of cost studies of intensive care units: problems with the cost concept. Crit Care Med 1995;23:964-72.

4. [No authors listed]. Guidelines for intensive care unit admission, discharge, and triage. Task Force of the American College of Critical Care Medicine, Society of Critical Care Medicine. Crit Care Med 1999;27:633-8.
5. Wild C, Narath M. Evaluating and planning ICUs: methods and approaches to differentiate between need and demand. Health Policy 2005;71:289-301.

6. Smith $\mathrm{G}$, Nielsen M. ABC of intensive care. Criteria for admission. BMJ 1999;318:1544-7.

7. Keenan SP, Doig GS, Martin CM, et al. Assessing the efficiency of the admission process to a critical care unit: does the literature allow the use of benchmarking? Intensive Care Med 1997;23:574-80.

8. Louriz M, Abidi K, Akkaoui M, et al. Determinants and outcomes associated with decisions to deny or to delay intensive care unit admission in Morocco. Intensive Care Med 2012;38:830-7.

9. Oglesby KJ, Durham L, Welch J, et al. 'Score to Door Time', a benchmarking tool for rapid response systems: a pilot multi-centre service evaluation. Crit Care 2011;15:R180.

10. Stelfox HT, Hemmelgarn BR, Bagshaw SM, et al. Intensive care unit bed availability and outcomes for hospitalized patients with sudden clinical deterioration. Arch Intern Med 2012;172:467-74.

11. Intas $G$, Stergiannis $P$, Chalari $E$, et al. The impact of ED boarding time, severity of illness, and discharge destination on outcomes of critically ill ED patients. Adv Emerg Nurs J 2012;34:164-9.

12. Robert R, Reignier J, Tournoux-Facon C, et al. Refusal of intensive care unit admission due to a full unit: impact on mortality. $A m \mathrm{~J}$ Respir Crit Care Med 2012;185:1081-7.

13. Sinuff T, Kahnamoui K, Cook DJ, et al. Rationing critical care beds: A systematic review. Crit Care Med 2004;32:1588-97.

14. Mardini L, Lipes J, Jayaraman D. Adverse outcomes associated with delayed intensive care consultation in medical and surgical inpatients. J Crit Care 2012;27:688-93.

15. Simpson HK, Clancy M, Goldfrad C, et al. Admissions to intensive care units from emergency departments: a descriptive study. Emerg Med J 2005;22:423-8.

16. Renaud B, Santin A, Coma E, et al. Association between timing of intensive care unit admission and outcomes for emergency department patients with community-acquired pneumonia. Crit Care Med 2009;37:2867-74.

17. Cardoso LT, Grion CM, Matsuo T, et al. Impact of delayed admission to intensive care units on mortality of critically ill patients: a cohort study. Crit Care 2011;15:R28.

18. Goldhill DR, McNarry AF, Hadjianastassiou VG, et al. The longer patients are in hospital before Intensive Care admission the higher their mortality. Intensive Care Med 2004;30:1908-13.

19. Huang $\mathrm{Q}$, Thind A, Dreyer JF, et al. The impact of delays to admission from the emergency department on inpatient outcomes. BMC Emerg Med 2010;10:16.

20. Chalfin DB, Trzeciak S, Likourezos A, et al. Impact of delayed transfer of critically ill patients from the emergency department to the intensive care unit. Crit Care Med 2007;35:1477-83.

21. Cabrini L, Monti G, Plumari VP, et al. Observed versus predicted hospital mortality in general wards patients assisted by a medical emergency team. Signa Vitae 2012;7:38-42.

22. Duke G, Green J, Briedis J. Survival of critically ill medical patients is time-critical. Crit Care Resusc 2004;6:261-7.

23. Parkhe M, Myles PS, Leach DS, et al. Outcome of emergency department patients with delayed admission to an intensive care unit. Emerg Med 2002;14:50-7.

24. Junhasavasdikul D, Theerawit $P$, Kiatboonsri S. Association between admission delay and adverse outcome of emergency medical patients. Emerg Med J 2013;30:320-3.

25. Giannini A, Consonni D. Physicians' perceptions and attitudes regarding inappropriate admissions and resource allocation in the intensive care setting. Br J Anaesth 2006;96:57-62.

26. Jäderling $\mathrm{G}$, Bell M, Martling CR, et al. Medical emergency team admittance to intensive care versus conventional admittance: characteristics and outcome. 32nd International Symposium on Intensive Care and Emergency Medicine. Crit Care 2012;16 (Suppl 1):507.

27. McQuillan P, Pilkington S, Allan A, et al. Confidential inquiry into quality of care before admission to intensive care. BMJ 1998;316:1853-8.

28. Cowan RM, Trzeciak S. Clinical review: emergency department overcrowding and the potential impact on the critically ill. Crit Care 2005;9:291-5.

29. Tang WM, Tong CK, Yu WC, et al. Outcome of adult critically ill patients mechanically ventilated on general medical wards. Hong Kong Med J 2012;18:284-90.

30. Intensive care society. Standards for intensive care units. Intensive care society, 1997. http://www.md.ucl.ac.be/didac/hosp/architec/ UK Intensive care.pdf

31. Grossmann FF, Zumbrunn T, Frauchiger A, et al. At risk of undertriage? Testing the performance and accuracy of the emergency severity index in older emergency department patients. Ann Emerg Med 2012;60:317-25.e3. 